\title{
Análise de hormônios em águas residuárias e naturais, derivada da extração com ponteiras descartáveis e detecção por HPLC-FL
}

Contaminantes emergentes apresentam, em ambientes aquáticos naturais, concentrações muito baixas, situando-se na faixa de $\mu \mathrm{g}$ L-1 a ng L-1, em alguns casos, níveis de concentração ainda mais baixos já foram analisados, portanto, torna-se necessário que o preparo de amostras seja eficiente para concentrar e minimiza as interferências para a determinação desses contaminantes emergentes. Este trabalho envolveu um estudo em que, a partir do uso de ponteiras descartáveis (DPX) fez-se a extração dos contaminantes emergentes, no caso os hormônios femininos, a partir de águas residuarias e naturais. Após o procedimento de extração fez-se a determinação dos hormônios presentes nas amostras de água através de Cromatografia Líquida de Alta Eficiência com Acoplamento de Fluorescência (HPLC-FL). Os resultados mostraram a presença de três hormônios nas amostras, o estriol, o B-Estradiol e o 17-a-Etinilestradiol, com concentrações na faixa de $\mu \mathrm{g}$ L-1. Esta mistura dinâmica da fase sólida dispersiva da amostra favorece o rápido equilíbrio de sorção do analito. Já a menor massa de sorvente, resulta em menores volumes de amostra e de solvente orgânico. Além disso, a extração por DPX pode ser facilmente automatizada juntamente com a deteç̧ão em HPLC-FL.

Palavras-chave: Hormônios; Preparo de amostra; DPX; HPLC-FL.

\section{Analysis of hormones in waste and natural waters, derived from extraction with disposable points and detection by HPLC-FL}

\begin{abstract}
Emerging pollutants present very low concentrations in natural aquatic environments, ranging from $\mu \mathrm{L} L-1$ to $\mathrm{ng}$ L-1, in some cases even lower concentration levels have already been analyzed, therefore, it is necessary that the preparation of samples is efficient to concentrate and minimize interference for the determination of emerging contaminants. This project involved a study in which, from the use of disposable tips (DPX), the emergent contaminants were extracted, in this case the female hormones, from wastewater and natural waters. After the extraction procedure, the hormones present in the water samples were analyzed by Fluorescence Coupling High-Performance Liquid Chromatography (HPLC-FL). The results showed the presence of three hormones in the samples, estriol, B-Estradiol and 17-a-Ethinyl estradiol, with concentrations in the $\mu \mathrm{g} \mathrm{L}-1$ range. This dynamic mixture of the solid dispersive-sample phase favors the rapid equilibrium sorption of the analyte. The lower sorbent mass results in lower sample and organic solvent volumes. In addition, DPX extraction can be easily automated along with HPLCFL detection.
\end{abstract}

Keywords: Hormones; Sample preparation; DPX; HPLC-FL.

Topic: Desenvolvimento, Sustentabilidade e Meio Ambiente

Reviewed anonymously in the process of blind peer
Received: 01/01/2021

Approved: 28/01/2021
Letícia Darlla Cordeiro (D)

Universidade Tecnológica Federal do Paraná, Brasil

http://lattes.cnpq.br/2212700919450121

http://orcid.org/0000-0003-1922-500X

leledarlla@gmail.com

Nelson Consolin Filho (iD)

Universidade Tecnológica Federal do Paraná, Brasil

http://lattes.cnpq.br/5820606948533146

http://orcid.org/0000-0002-4847-0701

consolin@utfpr.edu.br

Leonardo Valderrama (iD

Universidade Federal de Santa Catarina, Brasil

http://lattes.cnpq.br/8860556250381807

http://orcid.org/0000-0002-7166-8492

leovalderrama6@gmail.com

\author{
Oldair Donizete Leite (iD \\ Universidade Tecnológica Federal do Paraná, Brasil \\ http://lattes.cnpq.br/8436215509083608 \\ http://orcid.org/0000-0003-2554-3696 \\ oldairleite@utfpr.edu.br \\ Bianca Borsato Miskalo (iD \\ Universidade Tecnológica Federal do Paraná, Brasil \\ http://lattes.cnpq.br/2548026712897201 \\ http://orcid.org/0000-0002-7988-9476 \\ biancaborsato 1@msn.com \\ Marcilene Ferrari Barriquello Consolin (ib \\ Universidade Tecnológica Federal do Paraná, Brasil \\ http://lattes.cnpq.br/3028205116451785 \\ http://orcid.org/0000-0001-5499-2701 \\ marcilenef@utfpr.edu.br
}

Referencing this:

CORDEIRO, L. D.; CONSOLIN FILHO, N.; VALDERRAMA, L.; LEITE, O. D. MISKALO, B. B.; CONSOLIN, M. F. B.. Análise de hormônios em águas residuárias e naturais, derivada da extração com ponteiras descartáveis e detecção por HPLC-FL. Revista Ibero Americana de Ciências Ambientais, v.12, n.1, p.520-530, 2021. DOI:

http://doi.org/10.6008/CBPC2179-6858.2021.001.0042 


\section{INTRODUÇÃO}

Independentemente das discussões que cercam o tema da água, é possível fazer uma afirmação segura e indiscutível: a água é um bem natural, vital, insubstituível e comum. Nenhum ser vivo, humano ou não humano, pode viver sem a água. A ONU no dia 21 de julho de 2010, aprovou esta resolução: "a água potável e segura e o saneamento básico constituem um direito humano essencial".

Os meios hídricos são um meio receptor de esgotos domésticos, industriais e agropecuários e, portanto, são o principal veículo de dispersão ambiental dos poluentes químicos. Por este motivo, a problemática do ambiente e, mais concretamente, da água, continua a ser um tema atual a nível nacional e internacional (GAFFNEY et al., 2014).

Dentro desse tema envolvendo poluentes químicos em águas, podemos citar os contaminantes emergentes. Os contaminantes emergentes são compostos que têm sido detectados nos diferentes compartimentos ambientais, tanto os de origem antrópica como aqueles de ocorrência natural, que podem apresentar algum risco ao ecossistema e que não estão incluídos nos programas de monitoramento de rotina, ou seja, ainda não são legislados. Estes são candidatos a uma futura regulamentação dependendo dos resultados obtidos em estudos de ecotoxicidade, efeitos à saúde humana e animal, potencial de bioacumulação, transporte e destino no ambiente, além da concentração e quantidade em que são lançados no meio (PETROVIC et al., 2006). A descarga de contaminantes químicos emergentes para o meio aquático tem sido alvo de preocupação por parte da comunidade científica internacional, uma vez que, anualmente são sintetizados numerosos compostos químicos, os quais são lançados para o meio ambiente com consequências imprevisíveis, surgindo constantemente novas evidências sobre a sua toxicidade. (RICHARDSON et al., 2011).

Diversos grupos de substâncias têm sido considerados contaminantes emergentes, incluindo, novos agrotóxicos, drogas ilícitas, fármacos, produtos de higiene pessoal, protetores solares, estrogênios, alquilfenóis e seus derivados, alguns subprodutos provenientes de processos de desinfecção de água, retardantes de chama bromados, compostos perfluorados, siloxanos, benzotriazóis, ácidos naftênicos, percloratos, líquidos iônicos, dioxinas, o antimônio, além dos nanomateriais e alguns micro-organismos e toxinas de algas (RICHARDSON et al., 2011).

Tabela 1: Exemplos de ocorrência de alguns contaminantes emergentes no mundo em amostras de água superficial.

\begin{tabular}{|c|c|c|c|c|}
\hline Contaminante & Uso & $\begin{array}{l}\text { Concentração máxima } \\
\left(\text { ng L L }^{-1}\right)\end{array}$ & Tipo de corpo d'água & Local \\
\hline Cafeína & Estimulante & 16,1 & Mar & Alemanha \\
\hline $\begin{array}{l}17 \alpha- \\
\text { etinilestradiol }\end{array}$ & Anticoncepcional & 831 & Rio & EUA \\
\hline Estrôna & Hormônio & 22 & Rio & Espanha \\
\hline Amoxicilina & Antibiótico & 17 & Rio & Brasil \\
\hline Diclofenaco & Antiinflamatório & 266 & Rio & Costa Rica \\
\hline Atenolol & Anti-hipertensivo & 690 & Rio & Coréia do Sul \\
\hline
\end{tabular}

Fonte: Santana (2013).

Porém as concentrações de muitos contaminantes emergentes em ambientes aquáticos naturais são geralmente muito baixas, situando-se na faixa de $\mu \mathrm{g} \mathrm{L}^{-1}$ a $\mathrm{ng} \mathrm{L}^{-1}$. Em alguns casos, níveis de concentração 
ainda mais baixos já foram analisados (WEIGEL et al., 2002; KUCH et al., 2001). A Tabela 1 mostra alguns exemplos de contaminantes emergentes e suas referentes concentrações.

Contaminantes como o $17 \alpha$-etinilestradiol são também classificados como desreguladores endócrinos. Segundo a United States Environmental Protection Agency (USEPA), um desregulador endócrino é "um agente exógeno que interfere na síntese, secreção, transporte, ligação, ação ou eliminação de hormônios naturais que são responsáveis pela manutenção da homeostase, reprodução, desenvolvimento e/ou comportamento". Desreguladores endócrinos são capazes de minimizar ou bloquear a ação de hormônios no organismo. Estes também podem afetar a síntese, o transporte, o metabolismo e a excreção desses hormônios; desregulando, portanto, o sistema endócrino de cada indivíduo (GHISELLI et al., 2007). A Figura 1 mostra um esquema de como esses contaminantes podem chegar às redes de esgotos e posteriormente em águas superficiais.

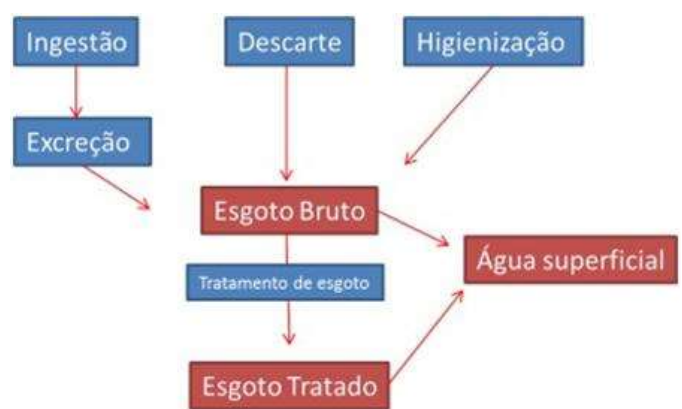

Figura 1: Meios de entrada de contaminantes emergentes em águas superficiais. Fonte: Santana (2013).

A partir da Figura 1 é possível analisar que contaminantes emergentes se dão por meios de descarte, seja na excreção, higienização ou mesmo nos rejeitos, que são atos praticados frequentemente por toda sociedade. Esse esgoto, tratado ou não, chega às águas superficiais levando ao aparecimento de muitas espécies químicas estranhas ao meio, incluindo os contaminantes emergentes. Há também outras fontes de contaminação, que incluem a lixiviação de substâncias e o lodo proveniente das estações de tratamento de esgoto (SANTANA, 2013). As estações de tratamentos de esgotos (ETE's) possuem quatro níveis de tratamento como podemos analisar na Figura 2.

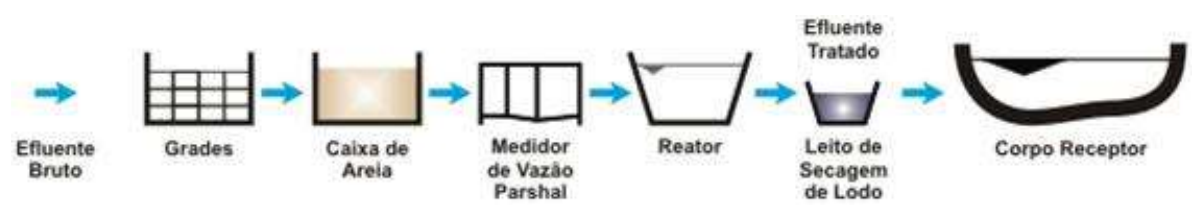

Figura 2: Meios de entrada de contaminantes emergentes em águas superficiais.

O tratamento preliminar objetiva apenas a remoção dos sólidos grosseiros, enquanto o tratamento primário visa a remoção de sólidos sedimentáveis e em decorrência, a parte da matéria orgânica. Em ambos predominam os mecanismos físicos de remoção de poluentes. Já no tratamento secundário, no qual dominam mecanismos biológicos, o objetivo é principalmente a remoção de matéria orgânica e eventualmente nutriente (nitrogênio e fósforo). O tratamento terciário objetiva a remoção de poluentes específicos (usualmente tóxicos ou compostos não biodegradáveis) ou ainda a remoção complementar de poluentes não suficientemente removidos no tratamento secundário (SPERLING, 2017). 
Entretanto o destino e os efeitos de contaminantes emergentes em águas brasileiras ainda têm sido pouco discutidos na literatura. Lembrando que a principal via de aporte deles em águas superficiais não está relacionada à contribuição dos efluentes de ETE, mas sim ao aporte de esgoto bruto, uma vez que aproximadamente $67 \%$ dos domicílios brasileiros não possuem rede coletora de esgoto e, apenas de $33 \%$ dos municípios tem acesso a esgoto tratado. Muitos municípios, apesar de coletar, descartam o esgoto bruto diretamente nos rios, mesmo aqueles que são utilizados como fonte de água para abastecimento público da região (IBGE, 2010).

Portanto tendo-se em vista esses níveis de concentração, é possível perceber a necessidade do uso de técnicas e métodos analíticos que apresentem limites de detecção baixos o suficiente para detectar a presença de contaminantes emergentes no ambiente.

A toxicidade de diversos poluentes ambientais tem sido habitualmente investigada quanto a sua teratogenicidade e carcinogenicidade em seres humanos e demais espécies. Nas últimas décadas, entretanto, o interesse de pesquisadores vem sendo despertado para os efeitos adversos sobre o sistema endócrino observados em alguns ecossistemas e animais de laboratório expostos a químicos ambientais.

Desreguladores endócrinos são moléculas pequenas que possuem a capacidade de mimetizar alguns hormônios esteroidais ou da tireóide, comprometendo os processos reprodutivos, de desenvolvimento e de manutenção da homeostase celular. Os desreguladores endócrinos podem perturbar o funcionamento do sistema endócrino, mimetizando hormônios naturais, estimulando a formação de mais receptores hormonais, bloqueando sítios receptores em uma célula,acelerando a síntese e a secreção de hormônios naturais, desativando enzimas responsáveis pela secreção de hormônios e/ou destruindo a habilidade dos hormônios em interagir com os receptores celulares (SODRÉ et al., 2007).

Esses efeitos prejudiciais podem levar ao desenvolvimento de doenças como câncer, desenvolvimento sexual anormal, como por exemplo, a redução da fertilidade masculina ou aumento nas chances de a mulher desenvolver ovário policístico. Essas substâncias também são prejudiciais ao desenvolvimento e reprodução de animais. Os estrógenos vêm sendo alvo de várias pesquisas pois são compostos extremamente ativos biologicamente e estão relacionados a vários tipos de câncer (SCHIAVINI et al., 2011).

Os hormônios são amplamente utilizados como método contraceptivo e em terapias de reposição hormonal, os naturais são produzidos pelo corpo humano e encontrados em rios e mananciais por meio da excreção da urina e fezes. A persistência da atividade dos estrógenos em ambientes aquáticos é devida, na maioria dos casos, à disposição inadequada de esgoto sanitário e industrial, pelo déficit de infraestrutura em saneamento, coleta ou tratamento.

Os estrógenos são usualmente analisados em água através das técnicas analíticas: Cromatografia Líquida de Alta Eficiência com detector de arranjo de diodos (HPLC-DAD, do inglês High Performance Liquid Chromatography - Diode Array Detection), com Detector de Espectrometria de Massas (LC-MS, do inglês Liquid Chromatography - Mass Spectrometry), com Detector de Fluorescência (LC-FL do inglês Liquid Chromatography - Fluorescence) e Cromatografia Gasosa Acoplada a Espectrômetro de Massas (GC-MS, do 
inglês Gas Chromatography - Mass Spectrometry) (VALDERRAMA, 2018).

\section{MATERIAIS E MÉTODOS}

\section{Coleta de amostras}

Para a determinação dos contaminantes emergentes, hormônios femininos coletaram-se amostras de esgoto bruto e tratado. Essa coleta foi realizada em uma Estação de Tratamento de Esgoto. Depois de coletadas, as amostras foram preservadas sob refrigeração $(0 \circ C)$ até a extração e análise.

As amostras analisadas são de cinco pontos diferentes da Estação de Tratamento de Esgoto, Afluente: esgoto bruto; Reator: esgoto em tratamento; Efluente: esgoto que sai tratado do reator; Montante: água do rio antes do despejo de efluente tratado e Jusante: água do rio, corpo receptor, da efluente tratado.

\section{Preparo das soluções}

Soluções estoque com concentrações de 1250, 1210, 1000 e $1000 \mathrm{mg} \mathrm{L}^{-1}$ foram preparadas para cada um dos hormônios incluindo 17 $\beta$-estradiol (betaEST), estrona (ETR), estriol (EST) e 17 $\alpha$-etinilestradiol (17-EE) respectivamente. A partir destas soluções preparou-se uma solução de trabalho incluindo todos os hormônios, na concentração de $250 \mathrm{mg} \mathrm{L}^{-1}$ em metanol (Sigma-Aldrich, St. Louis, USA). Nas ponteiras de 1 $\mathrm{mL}$, continham $20 \mathrm{mg}$ de Estireno-divinilbenzeno (VALDERRAMA, 2018).

\section{Preparo de amostras}

Valderrama (2018) realizou estudos de otimizações a fim de determinar a melhor condição para extração dos hormônios em água por DPX. Realizou estudos envolvendo, solvente extrator e dispersor, tempo de extração e dessorção, números de ciclos de extração, dessorção e limpeza, massa de solvente extrator e força iônica. A otimização dos parâmetros que afetam a técnica de DPX, como as melhores condições adquiridas por Valderrama (2018) foram adaptadas visando menores limites de quantificação. Realizou-se o preparo das amostras em triplicata, para que assim fosse possível obter um resultado mais preciso.

\section{Limpeza}

A escolha do solvente de lavagem é feita com base no tipo/natureza química do sorvente, no caso do trabalho o solvente escolhido foi a acetonitrila. A lavagem com solvente é também realizada por meio da entrada de ar na ponteira, é feita em 8 ciclos de 10 segundos com $200 \mu \mathrm{L}$ de acetonitrila, trocando o solvente a cada sucção, de acordo com o que está descrito na literatura.

\section{Extração}

A amostra é aspirada para o interior da ponteira, seguido da aspiração de ar, nessa fase realizou-se 5 ciclos de extração de $200 \mu \mathrm{L}$ permanecendo em aproximadamente 50 segundos na ponteira 


\section{Dessorção}

Realizou-se a dessorção em 8 ciclos de 10 segundos com o solvente acetonitrila, repetindo o mesmo solvente para a concentração do analito ficar mais alta, e pode ser diretamente injetado em um sistema cromatográfico, visando maior detectabilidade analítica. Todas as etapas envolvidas na extração por DPX são válidas para ambos os sistemas, manual e automatizado.

\section{Análise dos contaminantes emergentes}

A análise se restringiu a quatro compostos diferentes, estriol, $\beta$-estradiol, 17 etinil estradiol, estrôna. De acordo com a literatura Raimundo (2011), as concentrações dos hormônios são muito baixas, considerando essas condições, é necessário que o equipamento utilizado para as análises tenha alta sensibilidade, portanto a deteç̧ão foi realizada por meio de análises cromatrográficas utilizando Cromatografia Líquida de Alta Eficiência com Detector de Fluorescência, pertencente ao Departamento de Química da UTFPR- Câmpus Medianeira.

As amostras foram analisadas em um Cromatógrafo Líquido de Alta Eficiência (Prominence Shimadzu LC-20AT) com injetor manual (Rheodyne 7725i), sendo utilizado um detector de arranjo diodos (DAD) e Fluorescência (FL). A separação foi realizada empregando uma coluna em fase reversa sendo, a coluna de separação Phenomenex Kinetex C18 (4.6 mm d.i x $25 \mathrm{~cm}$ c x $5 \mu \mathrm{m}$ d.p.) e a coluna de guarda analítica Phenomenex Kinetex C18 ( $4 \mathrm{~mm}$ d.i x 1,5 cm cx $5 \mu \mathrm{m}$ d.p.). As condições cromatográficas utilizadas foram fase móvel gradiente com vazão de $1 \mathrm{~mL} \mathrm{~min}{ }^{-1}$ composta de água: acetonitrila (65:35, v/v), por 6 min, passando para (20:80, v/v) até 9 min, retornando então para condição inicial e finalizando a corrida em 15 min. O detector de fluorescência foi ajustado em comprimento de onda de excitação de $280 \mathrm{~nm}$ e comprimento de onda de emissão de $310 \mathrm{~nm}$. Os dados cromatográficos foram analisados pelo software LC Solution (Shimadzu, Kyoto, Japan). UHPLC: Ultimate 3000 Thermofisher (ultra-high performance liquid chromatography (Ultimate 3000, Thermo Scientific, Germering, Germany), equipado com um injetor automático de amostras, bomba quaternária, forno e conjunto de diodos (DAD) detector e fluorescência (FLD), e, controlado por Chromeleon 7.0 software).

\section{Análise estatística}

Os dados foram submetidos a uma análise estatística, utilizando o teste de Tuckey, a nível de significância 5\%, para a comparação das médias. O software utilizado foi o Portable Statistica 8.

\section{RESULTADOS E DISCUSSÃO}

\section{Determinação e avaliação dos hormônios}

Para fazer as análises do HPLC-FL foi injetado um mix contendo quatro hormônios, porém, apesar de todos os hormônios utilizados terem anéis aromáticos e ligações duplas somente três foram identificados no HPLC-FL como mostra a Figura 3. Pode-se observar pela Figura 3 a identificação desses hormônios como se 
segue: o hormônio Estriol apresentou tempo de retenção em 7 min representado como Composto 1, o hormônio $\beta$-Estradiol com tempo de retenção em 11 min representado como Composto 2, e, por fim o hormônio 17- a-Etinilestradiol com tempo de retenção de 13 min representado pelo Composto 3, o pico maior com tempo de retenção em aproximadamente 20 minutos pode ser considerado com um interferente. O fluxo foi de $0,3 \mathrm{~mL} \mathrm{~min}^{-1}$, contendo quatro compostos, com excitação de $230 \mathrm{~nm}$ e de emissão $310 \mathrm{~nm}$ obtidos com as condições cromatográficas estabelecidas para o método.

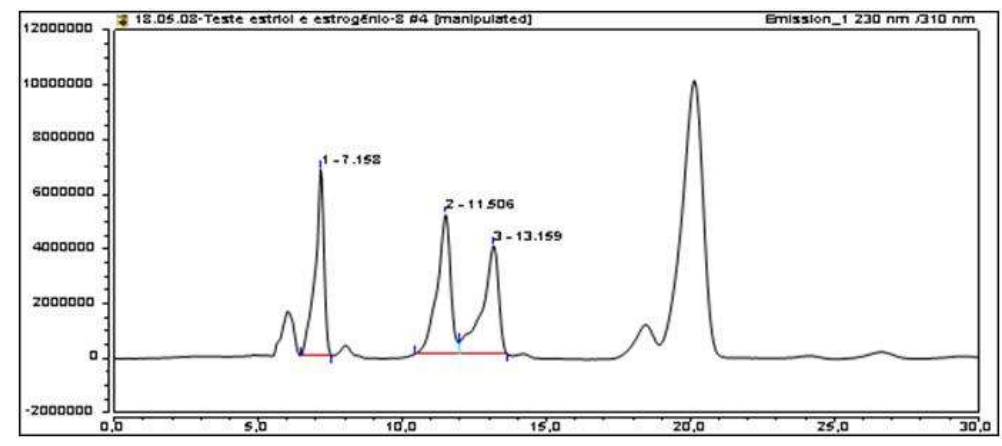

Figura 3: Cromatograma do mix de hormônios.

Tabela 2: Concentração $\left(\mu \mathrm{g} \mathrm{L}^{-1}\right)$ dos hormônios presente em cada amostra.

\begin{tabular}{cccc}
\hline Amostras & Estriol & 6-Estradiol & $\begin{array}{c}17-\boldsymbol{\alpha} \text { - } \\
\text { Etinilestradiol. }\end{array}$ \\
\hline Afluente & ND & $381,84 \pm 73,00^{\mathrm{c}}$ & $754,85 \pm 69,29^{\mathrm{b}}$ \\
\hline Reator & $786,64 \pm 3,138^{\mathrm{a}}$ & $1295,34 \pm 215,69^{\mathrm{b}}$ & $4441,25 \pm 571,83^{\mathrm{a}}$ \\
\hline & $\mathrm{ND}$ & $1631,91 \pm 124,55^{\mathrm{a}}$ & $\mathrm{ND}$ \\
\hline Efluente & $\mathrm{ND}$ & $\mathrm{ND}$ & $\mathrm{ND}$ \\
\hline Montante & & & \\
\hline Jusante & $315,76 \pm 25,57^{\mathrm{b}}$ & $136,55 \pm 2,225^{\mathrm{c}}$ & $313,84 \pm 39,05^{\mathrm{bc}}$
\end{tabular}

ND (não detectado). Média dos valores \pm desvio padrão; $n=3$. Diferentes letras na mesma coluna indicam diferença significativa $(p<0,05)$ pelo teste de Tukey. ${ }^{*} N D=$ Não Detectado.

Pelo teste de Tuckey, Tabela 2, foi observado que em todas as amostras a concentração dos hormônios diferiu de forma significativa. Esses resultados podem estar relacionados aos pontos de coleta das amostras. As amostras analisadas são de cinco pontos diferentes da Estação de Tratamento de Esgoto. Afluente é o esgoto bruto que chega na ETE proveniente de uma elevatória, a vazão média dessa estação é de $60 \mathrm{~L} \mathrm{~s}^{-1}$. A amostra deste ponto de coleta apresentou somente a presença dos hormônios $\beta$-Estradiol e 17$\alpha$-Etinilestradiol.

Na amostra coletada no Reator foi detectada a presença de três hormônios, o estriol, o $\beta$-Estradiol e o 17- $\alpha$-Etinilestradiol, e esta amostra foi a que apresentou a concentração mais alta de hormônios quando comparada as outras amostras coletadas para os diferentes pontos de coleta. No reator anaeróbio de lodo fluetizado acontece a digestão anaeróbia da matéria orgânica existente, dentro do reator contém bactérias acidogênicas e metanogênicas produzindo assim gás sulfídrico e gás metano, após essa digestão a afluente é mandado para uma lagoa de polimento. A presença dos hormônios em concentração mais alta nesta amostra pode estar relacionada ao fato de que neste ponto existe um acumulo de todos os efluentes recebidos e 
ainda em tratamento. Na amostra relativa ao ponto onde se tem a Efluente, observa-se que foi detectado a presença de um hormônio $\beta$-Estradiol, em concentração elevada.

Nessa etapa, a efluente sai tratado do reator anaeróbio de manto de lodo e entra em uma lagoa de polimento e posteriormente vai para o rio, chegando ao rio ele tem o ponto de despejo que é chamado de efluente tratado. A presença de somente um hormônio pode ser resultante do processo de tratamento, já que segundo Reis Filho et al. (2006) o processo de tratamento do esgoto é responsável por eliminar cerca de $90 \%$ dos contaminantes emergentes da água.

Na amostra coletada no ponto onde se denomina montante, não foi detectada a presença de hormônios. O montante do rio é 100 m antes do despejo do efluente, o montante serve para realizar uma análise das características do corpo receptor antes que o efluente seja despejado no rio, sendo assim, este corpo receptor, ou seja, este rio se encontra livre de contaminantes antes do despejo do efluente tratado.

Através dos resultados obtidos, observou-se que na amostra coletada no ponto jusante foram detectados os três hormônios o estriol, o $\beta$-Estradiol e o 17- $\alpha$-Etinilestradiol, em concentrações significativas. O ponto denominado como jusante é após a entrada do efluente no corpo receptor, a jusante serve para analisar quais foram os impactos causados pelo efluente no corpo receptor, então, é coletado $100 \mathrm{~m}$ para baixo da entrada do efluente no rio. O resultado encontrado para esta amostra pode estar relacionado ao fato de este corpo receptor estar a todo o momento recebendo Efluentes e apesar da amostra de Efluente coletada neste estudo ter apresentado somente a presença do hormônio $\beta$-Estradiol, outras Efluentes lançados neste corpo receptor podem estar contaminando.

Pode-se observar pela Tabela 2 que, das 5 amostras coletadas somente uma não apresentou a presença dos hormônios, a montante, as demais amostras coletadas apresentaram altas concentrações dos hormônios estudados, apresentando concentrações mais altas do que as encontradas na literatura, como mostra Araújo (2007) em seu trabalho onde as concentrações dos hormônios estão na ordem de 0,25 a 0,50 $\mu g \mathrm{~L}^{-1}$. Uma possível explicação para esses resultados é a grande quantidade de interferentes presentes nas amostras, assim apresentando coeluições que prejudicaram a precisão da análise.

Outra possível explicação é devido a origem da amostra ser de estação de tratamento de esgoto, portanto não foram realizados tratamentos dessas amostras e os hormônios realmente se encontram em concentrações altíssimas. Como se pode analisar nos resultados obtidos as concentrações desses hormônios estão em $\mu \mathrm{g} \mathrm{L}^{-1}$ (partes por bilhão). O problema é que, apesar dessas concentrações serem consideradas baixas para humanos, elas podem ter efeitos tóxicos para a fauna e a flora aquáticas. Há inclusive alguns estudos de autores como Bila et al. (2007) e Reis Filho et al. (2006) que relacionam a presença de hormônios femininos e outros contaminantes na água com a feminização de peixes e a formação de óvulos em animais machos, indicando que mesmo pequenas quantidades do estrogênio usado em pílulas anticoncepcionais podem levar ao colapso de algumas espécies. Mas os problemas referentes a desreguladores endócrinos presentes na água não param por aí, Bila et al. (2007) relatam ainda alguns efeitos como diminuição da eclosão de ovos de pássaros, peixes e tartarugas; problemas no sistema reprodutivo em répteis, pássaros e mamíferos e alterações no sistema imunológico de mamíferos marinhos, tem sido associado à exposição de 
espécies aos desreguladores.

Em humanos, além da diminuição de esperma no sêmen, também câncer de mama, de testículos e de próstata, além de endometriose. Portanto, é necessário melhorar o sistema de tratamento das ETE's, pois segundo Sodré et al. (2007) algumas ETE's que possuem sistemas de tratamentos mais inferiores, ou seja, contendo apenas três etapas (coagulação, sedimentação e filtração) são responsáveis por eliminar apenas $25 \%$ dos contaminantes emergentes, já ETE's com o sistema de lodo ativado podem reduzir até 90\% desses contaminantes pelo fato de que essa remoção de estrogênios da água durante o tratamento de esgoto é se dá por processos de biodegradação e adsorção nos lodos (SODRÉ et al., 2007).

Alguns trabalhos recentes apontam que esteroides vem sendo detectados em afluentes e efluentes de ETE's de vários países. Na Itália a média de concentrações de estregênios em ETE'S que operam com sistema de lodo ativado foram de 12, 52 e $3 \mathrm{ng} \mathrm{L^{-1 }}$ (BARONTI et al., 2000). Em ETE's britânicas essas concentrações variam de 1, 4 a 76 ng L $^{-1}$ (DESBROW et al., 1998). No Brasil hormônios foram detectados em ETE do Rio de Janeiro com concentrações médias de 21, 40 e 6 ng L-1 (TERNES et al., 1999).

Marques et al. (2010), comenta que ainda não existe um programa de monitoramento específico nas ETEs, impossibilitando o cálculo das quantidades de contaminantes emergentes que são removidos nas estações, principalmente porque o clima local e o regime de operação das unidades são fundamentais para se determinar o comportamento dessas substâncias durante a passagem pelas várias etapas de tratamento.

Segundo a legislação em vigor no Brasil, os parâmetros de potabilidade da água são determinados pela portaria no 2.914, de 12 de dezembro de 2011, publicada pelo Ministério da Saúde. Essa norma discute sobre as propriedades aceitáveis da água para consumo humano, como as relacionas à turbidez e ao pH, e as concentrações que são permitidas para várias substâncias químicas que apresentam risco à saúde, incluindo uma diversidade de agrotóxicos e pesticidas. Porém não há nenhuma previsão para fármacos ou hormônios (PIZZOLATO et al., 2017).

\section{Avaliação da técnica de ponteiras descartáveis}

Neste estudo, a utilização técnica DPX mostrou-se eficiente. Como citado anteriormente, contaminantes emergentes apresentam concentrações baixas segundo Almeida (2012). Sendo assim existe uma dificuldade no momento da deteç̧ão dos mesmos quando se utiliza amostras sem tratamento prévio.

A extração com a DPX permitiu a detecção desses contaminantes nas amostras de água residuária e natural de tal forma que foi possível não somente a identificação dos hormônios presentes como também a quantificação. A eficiência de extração com a DPX é baseada no tempo de equilíbrio de sorção entre a solução da amostra e a fase extratora. Desta maneira, o resultado encontrado mostra que quanto mais ciclos de extração forem realizados maiores serão as respostas de intensidades.

$\mathrm{Na}$ etapa de extração realizada neste estudo foram feitos 5 ciclos de extração permanecendo em aproximadamente 50 segundos na ponteira. Valderrama (2018), realizou estudos de otimização com o propósito de obter a condição ideal em relação ao tempo e ao número de ciclos de extração e dessorção para a análise de hormônios. Para isso, o autor empregou um planejamento multivariado composto central (em 
triplicata) do tipo Doehlert e obteve duas superfícies de resposta, sendo que a superfície de dessorção não apresentou uma situação de compromisso entre o tempo e o número de ciclos, 5 ciclos de 10 segundos ou 1 ciclo de 100 segundos. Seus resultados mostraram que as eficiências das duas condições são semelhantes, neste caso, foi escolhida a condição de 5 ciclos de 10 segundos, por apresentar um menor tempo de análise e eficiência um pouco superior para todos os analitos. Outro fator a ser considerado na aplicação da DPX é que quanto maior a afinidade entre o solvente de dessorção e o analito, maior será a eficiência com que este solvente realiza a dessorção do analito retido na fase extratora, melhorando a eficiência da extração.

É importante ressaltar que a técnica de preparo de amostra DPX foi otimizada por Valderrama (2018), onde em seu trabalho discute uma melhora significativa da técnica, otimizando as etapas de limpeza, extração de dessorção. Algumas das vantagens da técnica é que a extração do analito é utilizada uma pequena quantidade de sorvente. Esta técnica, como já citado, minimiza o tempo de extração, pois necessita de apenas poucos minutos para a obtenção de eficiente extração e favorece a ocupação de pequenos volumes de amostra e de solvente orgânico.

A técnica de DPX pode ter aplicação como ferramenta de baixo custo, podendo ser utilizada in sito no preparo de amostra para posterior determinação dos contaminantes para tratamento e qualidade de água em ambientes aquáticos e de abastecimento público. Essa possibilidade de uso tem uma importância imensa por causa do seu impacto ambiental, ao auxiliar na identificação de contaminantes encontrados em águas naturais que abasteçam diferentes comunidades, numa época em que a previsão para a qualidade da água potável no mundo neste século não é nada favorável.

\section{CONCLUSÕES}

Visando os resultados obtidos considera-se que o método DPX foi eficiente na determinação de hormônios juntamente com a detecção do HPLC- FL. Foi possível identificar os hormônios em quatro das cinco amostras coletadas, no afluente detectou-se os hormônios $\beta$-Estradiol e 17- $\alpha$-Etinilestradiol. No reator de loto detectou-se os três hormônios, Estriol, 6 -Estradiol e 17- $\alpha$-Etinilestradiol. No efluente foi possível detectar apenas o 6-Estradiol, no montante não foi detectado nenhum dos hormônios, mostrando assim que o rio estava limpo antes do efluente ser despejado, entretanto, na amostra do jusante detectou-se os três hormônios, toda via, o rio que estava limpo no momento em que o esgoto tratado é despejado em seu curso acaba sendo contaminado com os hormônios que estavam presente no efluente, gerando consequências para a fauna e flora presentes na natureza, e posteriormente sendo reingerida pelo ser humano através de centros de captação de água, causando assim mais danos à saúde humana.

O método de preparo de amostra além de ser simples, tem um tempo reduzido de trabalho. Também apresenta como vantagens o baixo custo do material e a praticidade devido ao uso da fase extratora comercial. Por outrolado, o HPLC-FL são ferramentas analíticas de alto custo. As concentrações dos hormônios encontradas na estação de tratamento de esgoto foram consideradas altas de acordo com o que está descrito na literatura, umas das possíveis explicações é que a água ainda estava em fase de tratamento, para um melhor resultado seria necessária realizar mais coletas e repetir os preparos de amostras e detecção, 
mas, devido ao curto prazo para a realização do trabalho não foi possível realizar mais repetições. Por fim, a combinação de métodos DPX e HPLC-FL, considerando a complexidade do sistema analisado, revelaram-se adequados e geraram resultados de interesse para a pesquisa sobre contaminantes emergentes.

\section{REFERÊNCIAS}

BARONTI, C.; CURINI, R.; D'ASCENZO, G.; DI CORCIA, A.; GENTILI, A.; SAMPERI, R.. Monitoring natural and synthetic estrogens at activated sludge sewage treatment plants and in receiving river water. Environmental Science \& Technology, v.24, p.5059-5066, 2000.

BILA, D. M.; DEZZOTI, M.. Desregulados endócrinos no meio ambiente: efeitos e consequências. Química Nova, v.30 n.3, 2007.

DESBROW, C.; ROUTLEDGE, E. J.; BRIGHTY, G. C.; SUMPTER, J. P.; WALDOCK, M.. Identification of estrogenic chemicals in STW effluent. Chemical fractionation and in vitro biological screening. Environmental Science \& Technology, v.32, p.1549-1558, 1998

GAFFNEY, V. J.; CARDOSO, V. V.; RODRIGUES, A.; FERREIRA, E.; BENOLIEL, M. J.; ALMEIDA, C. M. M.. Análise de fármacos em águas por SPE-UPLC-ESI-MS/MS. Química Nova, v.37, n.1, 2014

GHISELLI, G.; JARDIM, W. F.. Interferentes endócrinos no ambiente. Química Nova, v.30, n.3, 2007.

IBGE. Instituto Brasileiro de Geografia e Estatística. Censo 2010. Rio de Janeiro: IBGE, 2010.

KUCH, H. M.; BALLSCHIMITER, K.. Determination of Endocrine- Disrupting Phenolic Compounds and Estrogens in Surface and Drinking Water by HRGC-(NCl)-MS in the Picogram per Liter Range. Environ. Sci. Tech, v.35, p.3201, 2001.

MARQUES, D. M. L. M.; MULLER, G. T.; CENTENO, G. Esteróides em águas residuárias: estado da arte e perspectivas de tratamento. In: SIMPÓSIO INTERNACIONAL DE QUALIDADE AMBIENTAL, 7. Anais. 2010.

PETROVIC, M.; BARCELÓ, D.. Liquid chromatography-mass spectrometry in the analysis of the emerging environmental contaminants. Anal. Bioanal. Chem., v.385, p.422, 2006.

PIZZOLATO, T.; RAPOSO, C.. Resíduos de medicamento e hormônios na água preocupam cientistas. UFRGS-Ciência, 2017.

RAIMUNDO, C.. Contaminantes emergentes em água tratada e seus mananciais: sazonalidade, remoção e atividade estrogênica. Tese (Doutorado em Química Analítica) - Universidade de Estadual de Campinas, Campinas, 2011.

REIS FILHO, R. W.; ARAÚJO, J. C.; VIEIRA, E. M.. Hormônios sexuais estrógenos: contaminantes bioativos. Química. Nova, v.29, n.4, p.817-822, 2006

RICHARDSON, S. D.; TERNES, T. A.. Water analysis: emerging contaminants and current issues. Anal. Chem., v.83, p.4614 2011

SANTANA, J.. Determinação de contaminantes emergentes em mananciais de água bruta e na água para consumo humano do Distrito Federal. Dissertação (Mestrado em Química) - Universidade de Brasília, Brasília, 2013.

SCHIAVINI, J. A.; CARDOSO, C. E.; RODRIGUES, W. C. Desreguladores endócrinos no meio ambiente e o uso de potenciais bioindicadores. Eletrônica, v.4, n.3, p.33-48, 2011.

SODRÉ, F. F.; MONTAGNER, C. C.; LOCATELLI, M. A. F.; JARDIM, W. F.. Ocorrência de Interferentes Endócrinos e Produtos Farmacêuticos em Águas Superficiais da Região de Campinas (SP, Brasil). J. Braz. Soc. Ecotoxicol., v.2, n.2, 2007.

SPERLING, M. V.. Activated sludge and aerobic biofilm reactors. 4 ed. Iwa Publishing, 2017.

TERNES, T. A.; KRECHEL, P.; MUELLER, J.. Behavior and occurrence of estrogens in municipal sewage treatment plants - II. Aerobic batch experiments with activated sludge. The Science of the Total Environment, v.225, p.91-99, 1999.

VALDERRAMA, L.. Aplicação de calibração multivariada com integração de técnicas de microextração e detecção ótica para determinação de micropoluentes em matrizes complexas. Dissertação (Mestrado em Química) Universidade Federal de Santa Catarina, Florianópolis, 2018.

WEIGEL, S.; KUHLMANN, J.; HUHNERFUSS, H.. Drugs and personal care products as ubiquitous pollutants: occurrence and distribution of clofibric acid, caffeine and DEET in the North Sea. The Science of the Total Environment, v.295, p.131, 2002.

A CBPC - Companhia Brasileira de Produção Científica (CNPJ: 11.221.422/0001-03) detém os direitos materiais desta publicação. Os direitos referem-se à publicação do trabalho em qualquer parte do mundo, incluindo os direitos às renovações, expansões e disseminações da contribuição, bem como outros direitos subsidiários. Todos os trabalhos publicados eletronicamente poderão posteriormente ser publicados em coletâneas impressas sob coordenação da Sustenere Publishing, da Companhia Brasileira de Produção Científica e seus parceiros autorizados. Os (as) autores (as) preservam os direitos autorais, mas não têm permissão para a publicação da contribuição em outro meio, impresso ou digital, em português ou em tradução 